\title{
EL CORAJE INQUIETO DE LA UTOPÍA. DE LA DEMOCRACIA SUB-ALTERNA A LA DEMOCRACIA DEL CUIDADO
}

\begin{abstract}
The inquiet courage of the utopia. From sub-alternate democracy to the democracy of care
\end{abstract}

\section{Alessandro Serpe*}

\section{RESUMEN}

Democracia sub-alterna y Estado hegemónico. Crítica política desde América Latina ha sido uno de los últimos trabajos que la sabiduría del Profesor Álvaro MárquezFernández nos ha regalado. El volumen es rico de sugestiones y de inquietudes. En la obra dominan luces y sombras sobre la democracia, lugares donde el empeño teórico que el autor, con indómita pasión, ha capturado en el arco de su entera vida intelectual. El filósofo tiene en la mirada a las modernas y contemporáneas teorías sobre la democracia, que, culpables de convertir a la democracia en sistemas de poderes centralizados y jerarquizados, desconocen la exigencia de inclusión del otro. "Cuidado", "igualdad", "neoliberalismo" "utopía" son todas determinaciones que se reencuentran en las páginas del volumen, en diversas opciones teóricas del debate actual en filosofía moral, política y jurídica. El volumen abre con la perspectiva de convergencia paralela entre la "democracia sub-alterna" y la "democracia del cuidado". Con esta breve contribución, delineo el concepto de cuidado elaborado por la norteamericana Joan Tronto, y elaboraré líneas de semejanzas y diferencias entre los conceptos de "democracia del cuidado" según Tronto y la "democracia sub-alterna", en los modos del proyecto de socialismo utópico elaborado por Márquez-Fernández.

Palabras clave: Democracia Subalterna, Utopía, Socialismo, cuidado, Estado hegemónico.

RECIBIDO: Abril 2019

ACEPTADO: Mayo 2019

\section{ABSTRACT}

Democracia sub-alterna y Estado hegemónico. Crítica política desde América Latina has been one of the last works of Professor Alvaro Márquez-Fernández. The manuscript

* Profesor en Filosofía del Derecho. Università degli Studi “G. d'Annunzio di Chieti e Pescara, Italia. Correo electrónico: alserpe977@gmail.com 
is full of suggestions and significant issues, such as the lights and the shadows of democracy. It shows clearly the deep and uniquely theoretical commitment of the author over the course of his entire intellectual life. The philosopher focuses on the modern and contemporary theories of democracy whose assumptions lead to converting democracies into centralized and hierarchical systems of power, so disregarding the need for inclusion of the other. "Care", "equality", "neoliberalism", "utopia" are all determinations contained in the manuscript and, not less, in various theoretical conceptions of the current debate in moral, political and legal philosophy. The volume opens up a series of parallels and convergences between the concepts of "sub-alternate democracy" and "the democracy of care". In this brief contribution, I firstly outline the concept of care such as elaborated by the American Joan Tronto, and secondly I highlight some similiarities and differences between Tronto's concepts of "democracy of care" and the concept of "sub-alternate democracy" according to the utopian socialistic project developed by Márquez-Fernández.

Key Words: Subaltern democracy, Utopia, Socialism, Care, Hegemonic State.

\section{El latido de la democracia.}

Si la utilidad de un trabajo está en las preguntas que formula, en la comparación y en el diálogo, Márquez-Fernández, entre el coraje y los riesgos de la utopía, no ha faltado a sus promesas. Democracia sub-alterna y Estado hegemónico. Crítica Política desde América Latina es un volumen de límpida escritura, rico de sugestiones y matices. En esta obra dominan luces y sombras de la democracia que el autor, con indómita pasión, captura sabiamente envolviéndolas de fascinación. El programa es unitario: el lector ya experto conocedor de Márquez-Fernández, podrá fácilmente reencontrar los lugares de su compromiso teórico y los motivos que él ha sostenido en el arco de su entera vida intelectual. Democracia sub-alterna y Estado hegemónico es, una vez más, vivo testimonio de su incansable Verdad de teórico y filósofo frente a las inquietudes de su tiempo, de nuestro tiempo. No tengo en absoluto que exponer, en forma crítica el pensamiento complejo del Maestro Álvaro Márquez-Fernández cuya amplia producción comprende numerosos estudios, artículos, y manuscritos. Las estimulantes reflexiones del autor tendrían que ser puestas a prueba a través de distintas y particulares investigaciones. Hagamos una breve digresión. Nuestra larga correspondencia en el 
El coraje inquieto de la utopía. De la democracia sub-alterna a la democracia del cuidado

tiempo, estaba hecha de muchas pequeñas reflexiones sobre una pluralidad de temas: el derecho, la democracia, el poder. También después: las formas degeneradas del derecho, de la democracia, del poder, en una comparación entre Europa y América del sur. Aparece evidente la dificultad de representar en pocas palabras su pensamiento. No menos difícil es dar cuenta de la riqueza de las sugestiones contenidas en su último volumen Democracia sub-alterna y Estado hegemónico. Me limitaré aquí, a deslindar superficialmente las líneas teóricas que, en mi concepto, Márquez-Fernández presenta entre las páginas más significativas del volumen, para después iniciar una breve comparación de algunos aspectos entre su democracia sub-alterna y los recientes estudios sobre la democracia replanteada a partir de la ética del cuidado.

El cuidado es, en las espesas páginas de Márquez-Fernández, solidaridad, el bien intrínseco - a veces vislumbrado, a veces explícito - de la profunda estructura de la vida del individuo y de la sociedad. El proyecto de democracia sub-alterna, - escribe el autor -,

"busca explorar otros registros de participación comunitaria en base a la solidaridad y el bien en común que debe prevalecer como interés público para la ciudadanía" (Márquez-Fernández, 2018, p. 39)

Y, además, entiende poder contestar plenamente a la exigencia de "justicia y equidad, a las demandas sociales por medio de instituciones estatales que sean garantes de los derechos humanos" (Márquez-Fernández, 2018, p. 31).

La democracia sub-alterna muestra estar en condición de coparticipación en la esfera pública y en una alternativa propicia para la integración social de grupos marginados y excluidos (Márquez-Fernández, 2018, p. 78). La democracia sub-alterna es, para el autor, una forma de vida, lugar de diálogo, de discusión, de deliberación, de solidaridad política.

Con ejercicios de descomposición de los modelos tradicionalmente occidentales, Márquez-Fernández afirma la mutua relación entre ética y política: el espacio público es espacio de valores éticos y morales, condiciones imprescindibles 
Alessandro Serpe

Telos Vol. 21, No. 2 (2019). 497-516

para un actuar político inspirado a las exigencias de pluralidad y coparticipación (Márquez-Fernández, 2018, p. 49, 50). El elemento esencial del pluralismo está firmemente anclado a la ética pública del diálogo. Así, entre una visión holística del hombre y de la sociedad, Márquez-Fernández fija el connubio de legitimidad democrática y ética pública y diseña la democracia sub-alterna como "práctica democrática alternativa" (Márquez-Fernández, 2018, p.. 60, 62, 63)

El autor señala la urgencia de despejar del campo los modelos de la racionalidad política disciplinadas al utilitarismo, fuente de inspiración - en su forma de ver - de las democracias formales y representativas que, contrario a la democracia participativa, convierten al Estado hegemónico en un sistema institucional cerrado (MárquezFernández, 2018, p. 33, 76).

Márquez-Fernández tiene bajo su mirada las teorías modernas y contemporáneas de la democracia que, culpables de convertir las democracias en sistemas de poder centralizados y jerarquizados, desconocen la exigencia de inclusión del otro, de los marginados, o sea de los vulnerables, para usar un término del nuestro hoy (Márquez-Fernández, 2018, p. 58, 59). Pero el autor se lanza más allá: la democracia representativa es un lugar de poder cuyo intento es: minimizar y reducir la acción social del pueblo como destinatario de los poderes políticos" (MárquezFernández, 2018, p. 83).

La democracia participativa es, al contrario, por su parte, democracia popular, sinónimo de "libertades convividas y compartidas, en sentido aristotélico", un "ideal factible", lugar de lucha para la emancipación del Estado y del mercado neoliberal (Márquez-Fernández, 2018, p. 91). Estamos en un punto de gran fascinación: el Estado hegemónico" reviste las formas de la democracia representativa y privilegia el poder de la economía, la economía de mercado y de consumo, en perjuicio de la esfera subjetiva de vida de los ciudadanos. Márquez-Fernández marca los signos de crisis, internos y externos a la democracia: el capitalismo hegemónico, externo, pero así tan ínsito en la 
El coraje inquieto de la utopía. De la democracia sub-alterna a la democracia del cuidado

democracia, mortifica la democracia transformando la política en relaciones de producción económicas desdobladas a las siniestras exigencias del mercado. El neoliberalismo capitalista, que se ha insinuado a través de los mecanismos de la democracia representativa es, según Márquez, no solo motivo de disfunción de la política, sino más trágicamente motivo de deterioro de la convivencia humana (Márquez-Fernández, 2018, p. 84, 85). Las intensas páginas de Democracia sub-alterna y Estado hegemónico, tienen el latido de la democracia.

"Cuidado", "vulnerabilidad", "igualdad", "neoliberalismo", "utopía", son todas determinaciones que se reencuentran en el vivo pulsar de muchas y distintas opciones teóricas del debate actual en filosofía moral, política y jurídica. Dichas determinaciones son lugares más que recurrentes en la estructura de implantes teóricos que se han afirmado en el interior del pensamiento filosófico del último Novecientos: la ética del cuidado es grávida de ellas. Está en los perfiles de inquietud, mucho menos en aquellos de maduración y de resolución, que es posible trazar convergencias paralelas entre la democracia sub-alterna y la democracia del cuidado.

En esta breve contribución, tengo mi atención en la definición del cuidado elaborado por la estadounidense Joan Tronto, para la construcción de un modelo de democracia. No puedo eximirme del compromiso de introducir la Care ethics, trazando sumariamente, los orígenes y desarrollos políticos.

\section{Care Ethics. Una introducción.}

La ética del cuidado ha tenido su origen en los escritos feministas de la autora Carol Gilligan, la cual en su conocido trabajo "In a different voice" uniendo temas y métodos de la psicología moral, con aquellos de la filosofía moral, se preguntó sobre si y cómo los desarrollos morales dependían de las diferencias de género. En fuerte contraste con las teorías del psicólogo Lawrence Kohlberg, la referida autora llegó a la conclusión según la cual el trazo distintivo del razonamiento moral femenino, no tenía que encontrarse en una forma de inferioridad moral, en lugar que en una "voz moral" 
Alessandro Serpe

Telos Vol. 21, No. 2 (2019). 497-516

distinta. Mientras la ética masculina representa una ética de los derechos, ya que funda las decisiones morales en los principios abstractos de la justicia, de la igualdad, aquella femenina por su parte, mostrando sensibilidad hacia las consideraciones contextuales, las relaciones interpersonales, la empatía, encarna un modelo de ética del cuidado (Gilligan, 1982).

El elemento caracterizador de las distintas variantes de estudios se ha vuelto la vulnerabilidad entendida como fragilidad de cada ser humano. La vulnerabilidad es una noción estrictamente conexa con los estudios feministas: ella va entendida como condición necesaria para cada vida que denota la susceptibilidad física y psicológica al denegar, a la humillación, al abuso, al dolor, a la enfermedad.\} (Mackenzie, Rogers y Dodds, 2012)

En los últimos decenios, la ética del cuidado ha surcado distancias significativas con los precedentes estudios feministas basados en un exclusivo acercamiento de género. En efecto, desde el inicio de los años Noventa, los estudios de ética del cuidado, han virado hacia una dimensión más exquisitamente política. También autoras como Gilligan, Noddings y Held, representantes, en origen, de una visión feminista del cuidado, fundada en argumentos de naturaleza exclusivamente moral y psicológica, empezaron con el emprender estudios alrededor de las implicaciones del cuidado, en el ámbito político, cultural y social (Gilligan, 2010, p. 19-38).

Significativa, según ellas, aparece no más la exigencia de indagar la frágil y preciosa individualidad del individuo, a partir de las distinciones de orden sexual, en lugar de indagar sobre el cómo y el cuánto los asuntos fundamentales de la ética del cuidado, puedan contribuir a un cambio en las actitudes públicas de los individuos. En otras palabras, ha acontecido un cambio de la raíz profunda del trend: El cuidado no es más empresa normativa de naturaleza privada, sino más bien empresa normativa de naturaleza pública: el uso del care está orientado políticamente. 
El coraje inquieto de la utopía. De la democracia sub-alterna a la democracia del cuidado

El puente entre la política y el cuidado se vuelve, por así decirlo, instintivo. La revisión terminológica del cuidado en términos políticos y sociales ha tenido con seguridad que ver con la necesidad de individualizar formas de garantía y de protección de la frágil individualidad del individuo. El cuidado no es más entendido como expresión privada de inferioridad ligada a cuestiones de género, sino expresión desapegada de las prácticas públicas: ella se vuelve un elemento esencial de la fenomenología política.

A la luz de la siempre más creciente conciencia en relación al núcleo "políticamente" semántico del care, numerosos estudios se han alternado en el curso de los últimos decenios y han evidenciado, en estimulante medida, la mutua interacción e interrelación entre múltiples temáticas que circulan desde los derechos de las mujeres al derecho al trabajo, desde la ciudadanía política a las relaciones internacionales, desde la economía de mercado, a la economía política global. No pertenece a este breve ensayo reconstruir puntualmente las distintas posiciones en el ámbito de la ética del cuidado. No puedo que volver a evidenciar que, por breves trazos, aquello que, en mi parecer, representa el núcleo de las ideas fundamentales alrededor de la relación entre cuidado y democracia. Dejo al lado la dimensión de género en el análisis del concepto de cuidado: Joan Tronto, con la finalidad de señalar algunas singulares concordancias de lugares, nudos y problemas alrededor de la democracia sub-alterna y la democracia del cuidado. Sugiero llamar en seguida la atención a un tema decisivo: la reconsideración de la democracia a partir del cuidado.

A partir de las reflexiones de Gilligan, pero con cauta distancia desde los excesos del elitismo de género y de los abstraccionismos orientados a dicotomías y a jerarquías, Tronto alumbraba el nuevo "sentido" de concepto de care con estas lindas palabras

"Care is nonetheless a universal aspect of human life. All humans need be cared for, though the degree of care that other must provide depends not only upon culturally constructed differences, bat also on biological differences that human infants are not capable of caring for themselves, and that stick, infirm, and deal human need to be taken care of (...) care is not universal with regard 
to any specific needs, but all humans have need that others must help them meet" (Gilligan, 2010 p. 110)

[el cuidado es un universal aspecto de la vida humana. Todos los seres humanos necesitan cuidado, a pesar del grado de cuidado que los otros deben proveer, depende no sólo de las diferencias culturales construidas, sino también en las diferencias biológicas que los infantes no son capaces de cuidarse asimismos, (...) el cuidado no es universal con referencia a algunas específicas necesidades, pero todos los seres humanos tenemos la necesidad de que los demás deben ayudar a cumplir].

Desde estas palabras surge, en mi concepto, la carga no solamente moral, sino aquella política del concepto de care: El cuidado no debe relegarse ni al ámbito de las emociones o de los principios, ni mucho menos debe reencontrarse en los túneles del pensamiento moral femenino. En su trabajo pionero, Moral Boundaries, 1993, Tronto aun colocándose en el cauce de los estudios sobre el feminismo, trataba de mostrar cuánto el care pudiera ser repensado, variado y retraducido, con argumentos políticos. Y todo lo anterior con efectos del peso por lo que refiere a la idea misma del cuidado: adquiriendo una valía política, el término sirve para prescribir el ideal de una política más pluralista y más democrática (Tronto, 1993: p.21). En lo que refiere al concepto político, el cuidado es una práctica que involucra pensamientos y acciones, acciones y finalidades. La interdependencia de pensamientos, acciones, y finalidades entre la estructura de la práctica hace que el cuidado asuma una dimensión universal. Tronto daba fuerza y consistencia a una intuición contenida en un trabajo escrito hace en 1991 con Berenice Fisher. Las dos autoras habían interpretado el cuidado como.

"a species activity that includes everything that we maintain, continue and repair our "world" so that we can live in it as well as possible. The world includes our bodies, our environment, and ourselves, all of which we seek to interweave in a complex, life sustaining web" (Fisher y Tronto, 1991 p. 40). [algunas actividades específicas que incluyen todo lo que se refiere a mantenimiento, continuación y reparación de nuestro "mundo" para que podamos vivir en él lo mejor posible. El mundo, continuaban las autoras, incluye nuestros cuerpos, nuestro medio ambiente y nosotros mismos, todos lo cual buscamos entrelazar en una red compleja y sustentadora de la vida]. 
El coraje inquieto de la utopía. De la democracia sub-alterna a la democracia del cuidado

En aquella definición, existía ya la negación de confinar el cuidado dentro de los recintos del ámbito privado y la urgencia de elevarlo a un elemento del discurso público.

En la apelación a la dimensión política del término, se advierte algo todavía más decisivo: la crisis de los modelos éticos que subyacen a la visión política. Ella, exaltando por un lado la dimensión de la socialidad y de la afinidad del individuo, y por el otro, teniendo a distancia los excesos del existencialismo biológico y el miope nexo con la moralidad femenina, entraba así, en las fibras de la filosofía moral. Es desde la filosofía moral que hay que moverse ya que ella es el terreno en el cual el cuidado muestra su carga de valor distintiva. No basta descomponer los viejos modelos éticos de la tradición Occidental, hay que saltar los confines morales y reafirmar la mutua relación entre ética y política. Solamente así, según Tronto, la ética del cuidado puede afirmarse como alternativa sustancial y asistir a la política en términos de pluralismo y de democracia. Para una política que entienda ponerse el objetivo de cuidar los individuos y su frágil individualidad, no hay más camino.

Tronto (1993) llama a juicio los tentativos estratégicos justificadores de la autoridad política: la filosofía kantiana y no menos, el neo-contractualismo de Rawls y de Habermas, a lo largo del eje que une a Hobbes, Locke y Kant. Si bien por razones distintas y con resultados diferentes, Kant, Rawls y Habermas son acusados de haber escondido el elemento de la emocionalidad del individuo en el signo de una abstracta racionalidad, alejada de la realidad, con la finalidad de intentar una definición de sociedad "ecua y justa". El poder exige sí un fundamento moral, pero el abstractismo, el impersonalismo y el universalismo persiguen un espejismo de una fácil riqueza: hacer corresponder a una presunta razón universal, una presunta moralidad universal, causante, a su vez, de una presunta igualdad. La obstinación con la cual sobreviven los modelos de racionalidad y de pureza del actuar moral, son reliquias del pasado, objeto de un culto perversamente inspirado en justificar el status quo político. 
El cuidado, como complejo de prácticas está articulado - según Tronto - en cuatro fases interdependientes, pero analíticamente separadas, de la relación de ayuda: caring about (Iinteresarse en), taking care of (tomarse cuidado de) care-giving (prestar cuidado), care receving (recibir cuidado). La primera fase está caracterizada por el reconocimiento de la necesidad de los demás; La segunda por la posibilidad de hacer algo por el otro; La tercera para prestar cuidado. La cuarta fase está caracterizada por la respuesta del diálogo en relación a la completitud y a la satisfacción de las necesidades por parte del destinatario del cuidado: sólamente interrogando el care- receiver será posible establecer si el trabajo del cuidado ha sido eficaz (Tronto, 1993 p. 40). Como es fácil notar, los aspectos del proceso del cuidado presuponen escogencias de valor: la atención (attentiveness), la responsabilidad (responsability), la competencia (competence) y la receptividad (responsiveness), a las cuales corresponden las cuatro fases anteriormente descritas, son calidades éticas.

El entramado de formas y valores se muestra particularmente interesante entonces por lo que el cuidado es transportado al nivel superior de la dimensión pública: el estadio democrático. El corazón normativo del cuidado encuentra expresión en una quinta fase: caring with. La simple preposición with, (con) es un elemento de conexión que expresa y establece una relación: el "cuidado con" requiere que las fases anteriores hayan sido cumplidas cada una por sí misma y todas en su conjunto, de conformidad con el compromiso democrático por la justicia, la igualdad y la libertad de y para todos (Tronto, 2013). Ciudadanía y cuidado interactúan en tal forma que la democracia no es reducida a un mero procedimiento de ritos fríamente solemnes. Al contrario: ella se vuelve una forma de gobierno que se funda y requiere la participación de ciudadanos responsables, comprometidos e involucrados en prácticas de care with, o sea, en prácticas dirigidas al cuidado por el otro y al cumplimiento de los valores de libertad, 
El coraje inquieto de la utopía. De la democracia sub-alterna a la democracia del cuidado

igualdad y justicia. En esta visión, cuidado y política no caen en la dicotomía "privado" "público", ni en aquella "dimensión moral femenina" y "dimensión moral masculina"1.

La práctica del cuidado hace que el individuo se reconozca no solamente responsable de sí mismo y de su existir sino también del otro y de su existir. El individuo no es un centro vital autónomo, pero es al mismo tiempo portador y destinatario del cuidado, dentro de una trama de relaciones democráticamente sociales.

Las reflexiones de Tronto, tienen una singular actualidad: ellas no se detienen en la reevaluación del pensamiento moral, sino que hacen cuentas con las vulnerabilidades difundidas en muchos estratos sociales. En esto aparecen ineludibles las convergencias entre las reflexiones de Tronto y aquellas de Márquez-Fernández. La democracia del cuidado es además denuncia de las iniquidades del capitalismo global. El arco dentro del cual se mueven las críticas al neoliberalismo es una vez más aquel del confín entre ética y política: la neta distinción entre los dos campos corroboraría las actuales perspectivas morales que, ondeando la bandera de la imparcialidad esconden el otorgamiento de beneficios, privilegios y poderes en cabeza de pocos. En sintonía con los aspectos críticos del Holmes y Sunstein, respecto a las ilusorias creencias en la autonomía y en la libertad del individuo, como entidad racional y centro de imputación de escogencias y responsabilidades (Holmes, 1999, p.204), Tronto rechazaba firmemente la configuración neoliberal del individuo como homo economicus, criatura y servidor del mercado que modelando sus escogencias sobre la base del frío cálculo de la utilidad, se abandona a una indolente y apática indiferencia moral (Tronto, 2013, p. 38-40). El pensamiento hegemónico de matriz neoliberal está viciado de un exceso de abstractismo que considera - con las palabras de Tronto - Las personas como

\footnotetext{
${ }^{1}$ A respecto es interesante notar que el acercamiento anti-dicotómico de Tronto se diferencia de aquel biológico de L.D. Campbell, M.P. Carroll, The incomplete devolution - theroizing gender when studying men who provide care to aging parents, in: "Men and Masculinities", 9, 4, 2007, p. 491-508, de aquel Psicológico di N. Chadorow, Mothering, objectrelations, and the female oedipal configuration, en: "Feminist Studies", 4, 1, 1978, p. 137-158; Id., The reproduction of mothering: psychoanalysis and the sociology of gender, Berkeley 1978, e de aquel cultural y de género de C. Gilligan, D.A.J. Richards, The deepening darkness; patriarchi, resistence, and democracy's future, New York, 2009.
} 
Alessandro Serpe

Telos Vol. 21, No. 2 (2019). 497-516

trabajadores y como consumidores, sujetos autónomos conscientes de sus preferencias (Tronto, 2013, p. 38).

También aquí hay alguna analogía entre Tronto y Márquez-Fernández: el individuo es arrastrado por el ciclón del neoliberalismo. Para Tronto, el telón del abstractismo responde a exigencias de aparente neutralidad: La ideología neoliberal esconde diferencias y vulnerabilidades sociales. Si el neoliberalismo favorece el desarrollo de políticas económicas orientadas al progreso y finalizadas a la acumulación de riqueza ella no puede llamarse teoría económica descriptiva. El neoliberalismo se descubre ser un sistema ético, una ideología. De aquí sigue una incompatibilidad estructural entre "libre mercado" y "cuidado del otro", entre individualismo y protección de la vulnerabilidad. Contra los peligros ínsitos en las tranquilizadoras éticas racionalistas - de Kant, a Rawls, de Habermas, a Von Hayek, de Nozick, a Taylor - Los cuales aún por distintas exigencias y con distintos acentos tratan de elaborar grandes categorías normativas - la libertad, la autonomía, los derechos, la justicia distributiva Tronto tiene en sus páginas otra vía para un "Nuevo Inicio".

En la perspectiva de la democracia del cuidado, el sujeto de la vida política no puede ser en último análisis la economía, el libre mercado y la responsabilidad personal. El punto de intersección entre política, cuidado y democracia está bien representado por la definición de política "as a way to divide up responsibilities: who is responsible for caring what when where and how" (Tronto, 2013, p. 46). El hombre político virtuoso asigna las responsabilidades para el cuidado entre los ciudadanos, individualizando el quién, la cosa, el cuándo, y el cómo. El modelo de la ética del cuidado puesto al interior de la sociedad, se hace responsabilidad del cuidado, participación activa de los ciudadanos, care with.

En discusión no es más que el hallazgo de un principio individual ni la resolución de conflictos entre principios en abstracto. La política es la arena pública cuyos fines, poderes y pluralidades se evidencian volviendo objeto de debate y de 
El coraje inquieto de la utopía. De la democracia sub-alterna a la democracia del cuidado

deliberación. La democracia del cuidado no es distribución de recursos y poderes: ella es democracia inclusiva en la distribución de responsabilidades, es un proceso de cuidado individual e institucional para cada uno de nosotros y para todos nosotros, y por lo tanto individual, individual e institucional. No es difícil reconocer, una vez más algunas sintonías entre las razones propias de la democracia del cuidado y aquellas de la democracia sub-alterna.

\section{Desde el cielo azul a los hechos duros. Democracia del cuidado y Democracia sub-} alterna.

La lección de Tronto (1993) es sin duda rica de sugestiones cautivadoras. Pero en seguida que nos alejamos del cielo azul de los conceptos, se corre el riesgo de estrellarse contra hechos duros como la roca. El cielo de la utopía es seda, el cielo de los hombres es cáñamo. Por cuanto sea noble el ideal de una práctica auténticamente democrática, dirigida a la distribución de cuidado y de responsabilidad, el hecho que sean las instituciones, los lugares en los cuales se reconocen las necesidades y se discuten y se determinan las finalidades y los objetivos del cuidado y de la responsabilidad, nos lleva inexorablemente al desencanto de la política. O dicho en otra forma, con las notas del pentagrama de Tronto: ¿quién determina las necesidades? ¿Qué los determina? ¿Cuándo y cómo se los determinan?

El cuidado es un concepto normativo que sugiere direcciones de pensamiento y de acción dentro de una visión ética y social de la democracia, como respuesta al malestar que envuelve una sociedad disciplinada en perspectivas morales, sedicientes, imparciales y universales. Esto está implícito en el tentativo teórico de sentar las bases teóricas del sistema ético, político y jurídico en el concepto de cuidado. Es cómodo convenir en el hecho que la ética del cuidado está elevada a un ideal político de una democracia que escucha las voces de todo el mundo, no solamente aquella de los potentes. La democracia del cuidado es un ejercicio virtuoso de ciudadanía para la construcción de una cultura éticamente y civilmente responsable. 
Se podría objetar a Tronto (1993), si el cuidado constituya un correctivo conceptual o por lo menos suministre un modelo alternativo a aquel de la justicia de tradición liberal. Podría ser lícito preguntarse si el cuidado se limita a desplegar razones en contra, o si representa un verdadero reto a las tradicionales teorías éticas, políticas y jurídicas, inspiradas en el pensamiento liberal. ¿Son la democracia del cuidado, y no menos la democracia sub-alterna, modelos idóneos para detener los riesgos de paternalismos y particularismos? ¿O de pronto discernir entre ética y política es una operación teórica más sobria y saludable para la democracia? Y además: ¿el liberalismo político ignora el cuidado, el tomar cuidado y, en su múltiple riqueza, la igualdad?

Poniendo a un lado cuestiones exquisitamente lingüísticas en relación al área de denotación y a las formas de indeterminación del término care, y quedando en un nivel más general de discusión, me detengo brevemente sobre tres perfiles igualmente interesantes.

El primero: el cuidado es, primero y río arriba, una virtud moral constitutivamente ligada a la esfera privada del actuar. Ella es una disposición, una propensión, una actitud personal. A pesar de lo anterior, la política, la esfera pública del actuar, necesita sea del cuidado que de cualquier otra virtud moral - la prudencia, la sabiduría, la justicia, la templanza: ellas constituyen las sub-estructuras para la construcción de una sociedad civil y democrática. La búsqueda y la necesidad de un anclaje moral para nuestras sociedades azotadas por repentinos cambios y por desórdenes sociales y políticos es lo reivindicado por los sostenedores de la ética del cuidado. Pero ellos no están solos en esta arena. La idea que todo sea política y que la política sea todo es seguramente peligroso: no se puede - tengo en la mente un lindo pasaje de Bobbio - cultivar la filosofía política sin entender lo que yace detrás, sin aventurarse en la esfera no propiamente política y sin intentar establecer algunos confines entre lo político y lo no político (Bobbio, 2000: p. 28). Todavía también si las virtudes morales, bien o mal que sea, pueden expresarse y formularse con el lenguaje 
El coraje inquieto de la utopía. De la democracia sub-alterna a la democracia del cuidado

de la política, ellas pertenecen a la esfera de lo no-político. Con seguridad podemos invocarlas a precondiciones del florecimiento de los individuos de la sociedad, del buen vivir social; podemos además adoptarlas como criterio de reflexión crítica acerca del florecimiento de los individuos, de la sociedad y del buen vivir social; podemos, no obstante, componerlas, valorarlas y medirlas dentro y por una teoría de la democracia. Sin embargo, ellas quedan como virtudes no-políticas.

Estamos en el segundo perfil. Añadiría, pero no como contorno, que el liberalismo político no va en la dirección opuesta con respecto a la ética del cuidado. El liberalismo es la doctrina que sostiene la limitación de los poderes y de las funciones del Estado en favor de la libertad. Se necesitan algunas libertades a la existencia y al ejercicio del poder democrático: libertad de opinión, de expresión de reunión, de asociación de medios. Aquellos de Locke, Montesquieu, Kant, Smith, Mill han sido a pesar de las distintas intensiones de sus trabajos, experimento de resistencia contra las injerencias públicas: al Estado no le queda que dejarse configurar como garantía institucional de la libertad. La historia del liberalismo es historia sangrienta de libertades civiles y libertades políticas: el liberalismo ha luchado a favor de la emancipación contra los poderes y contra los abusos de naturaleza religiosa, política y económica para la construcción de un Estado liberal. El Estado democrático no es solamente la "prosecución natural" del Estado liberal, sino también su presupuesto jurídico (Bobbio, 2006: p. 47). Queda entendido que los límites entre los cuales el Estado democrático ejerce su poder no son más aquellos que derivan del principio de legalidad formal, principio destinado a proteger los individuos de la injerencias públicas, en lugar de aquellos que derivan de los derechos de libertad constitucionalmente reconocidos y garantizados (Serpe, 2015, p.18).

Si de un lado, liberalismo y democracia comparten la eterna vocación a la libertad del individuo y revindican su primacía ontológica y axiológica en relación con la comunidad, por el otro lado, liberalismo y democracia no ignoran en absoluto la igualdad. Si miramos a la igualdad con ojos desencantados y la desnudamos de su 
Alessandro Serpe

Telos Vol. 21, No. 2 (2019). 497-516

significado profundamente emotivo, ella es, y no puede no ser, que una relación formal, una condición de hecho, un criterio formal de justicia, una especificación de la máxima sum cuiuque tribuere: "todos los hombres son iguales", "todos los hombres son iguales frente a la ley". El punto crucial es el siguiente: si los contenidos del principio de igualdad están determinados por las ideologías igualitarias, el liberalismo por su lado no es ni el revés ni la antítesis del igualitarismo. El liberalismo declina la igualdad en los términos de igual libertad de los hombres y "admite - con las palabras de Bobbio la igualdad de todos no en todo (o casi todo) pero solamente en alguna cosa y este "alguna cosa" son habitualmente los derechos fundamentales, o naturales, o, como se dice hoy, humanos" (Bobbio, 2009, p. 36). Como es fácil notar, el liberalismo nos divide con un corte neto de libertad e igualdad, en su lugar establece la recíproca y profunda interconexión. De lo que emerge, el llamado al cuidado no puede definirse peculiaridad exclusiva de la ética del cuidado.

Estas últimas consideraciones trazan una significativa discrepancia con los modelos de democracia del cuidado y de democracia sub-alterna. Pero no termina aquí, también entre los dos modelos de democracia media una significativa divergencia.

Se ha llegado a un último punto de gran fascinación, pero no menos complicado. Si por un lado la ética del cuidado de Tronto, estimula las críticas a la concepción individualista a la autonomía y de la autosuficiencia profesada por el liberalismo sirviéndose de los "instrumentos" del cuidado, de la dependencia y de la relacionalidad, por el otro ella no entiende descomponer, derribar o socavar el nexo entre democracia y liberalismo. Esta es, en mi opinión, la clase más iluminante y significativa.

El punto de intersección entre democracia, por un lado, y liberalismo y socialismo por el otro, está en las declinaciones de democracia representativa y directa. En términos breves, para los liberales la democracia es democracia representativa, la única forma compatible con los valores fundamentales de la libertad y de la igualdad en 
El coraje inquieto de la utopía. De la democracia sub-alterna a la democracia del cuidado

términos de libertad. La doctrina socialista requiere un fortalecimiento de la base popular y replantea fuertemente los temas de la doctrina de la soberanía popular. Para ambas la democracia es participación en la vida pública, pero con una no pequeña diferencia: para los liberales, la participación es representación a través de órganos colegiados elegidos por el pueblo sobre la base del sufragio universal cuyas decisiones son adoptadas según el principio mayoritario. El socialismo no amarra las suertes del parlamentarismo a aquellas de la democracia: "participación" con los socialismos asume un significado que va más allá de la intervención directa de los ciudadanos en las decisiones colectivas, volcándose hasta incluir las relaciones económicas. Mientras que, para los liberales, el ejercicio de la libertad política, es sufragio universal es el punto de llegada del proceso de democratización del Estado, para el socialismo el sufragio universal, para decirlo con el acumen de Bobbio, "constituye solamente el punto de partida" (Bobbio, 2004, p. 268). El feliz encuentro entre democracia del cuidado y democracia sub-alterna termina aquí.

\section{El coraje inquieto de la utopía.}

Frente a las dificultades sobre la consistencia de la democracia, sobre las dificultades encarnadas hace un tiempo en el nazismo, en el fascismo y en el comunismo y en nuestros días, en el neoliberalismo y en la globalización, parar el juego de seducción del lado emocional de las personas con sobrios ejercicios de disciplinado análisis del concepto de democracia, es operación saludable. Encerrar el significado de democracia por las vías de la definición ha servido para encauzar los riesgos de usos persuasivos de democracia por obra de los regímenes nacistas, fascistas y comunistas y, en los años más recientes, puede mostrarse útil para mantener a raya aquellos puestos en campos por gobiernos socialistas y por los Países del tercer mundo. La manipulación del uso de "democracia" degrada la nobleza de los ideales, revolucionarios y/o burgueses que sean, y las doctrinas de los derechos humanos que están río arriba. 
Desde una perspectiva liberar el fulcro de los derechos de las libertades individuales es ciertamente la primera condición. A este respecto así escribía Kelsen: "La democracia moderna no puede ser separada del liberalismo político. Su principio no debe interferir en ciertas esferas de intereses propias delo individuo que deben ser protegidas por la ley como derechos humanos fundamentales o derechos de libertad" (Kelsen, 1988, p.245).

Todavía, como se ha podido mostrar, el liberalismo no ve resuelta su especificidad de ideal de salvaguarda y protección de las libertades individuales con la participación directa e indirecta de la vida política; los derechos de libertad se completan con aquellos sociales, precisamente con el trámite de la democracia. La democracia representativa no es a mí parecer, ni un exceso ni un estorbo. Autodeterminación y autonomía de pensamiento por un lado e igualdad en la libertad por el otro están en íntima afinidad, ideales innegables por cada democrático que entienda cuidarse del otro. La democracia representativa concilia, en la vía abierta por Mill, la necesidad humana de independencia con el reconocimiento de la leadership y la necesidad de competencia en la vida política. Recuerdo solamente por un momento el significado que este binomio ha tenido en el segundo Ochocientos, y todavía en la cultura jurídica y política europea del segundo Novecientos. La esencia de la democracia, está justamente en el hacer del pueblo y sus representantes, partícipes de las escogencias y de las decisiones políticas: soberanía popular y representación, en las formas de la leadership y de la competencia, están íntimamente conectados (Ross, 2016, p.25).

A través de un continuo activo ejercicio de la soberanía popular en el respeto de la regla de la mayoría se podrá garantizar, no solamente la evolución y el cambio del sistema político y jurídico, sino también la composición y la resolución pacífica de los conflictos en vista de la evolución del cambio. El pueblo es soberano, pero es difícil 
El coraje inquieto de la utopía. De la democracia sub-alterna a la democracia del cuidado

imaginar que cada decisión Estatal pueda ser tomada inmediatamente por todos, por todo el pueblo a través de los plebiscitos.

Con lo que se ha sostenido, no se quiere constreñir la democracia en formulas rígidas y en prácticas burocratizadas. Ni mucho menos relegar la ética a un plano exquisitamente teórico y de mero ejercicio académico, descontextualizado y lejos de la realidad. Las vías para una más robusta distribución del cuidado y de la responsabilidad en la forma de la democracia del cuidado, o el desarrollo de reformas en dirección socialista en las formas de la democracia sub-alterna, son transitables en la preservación de la forma de gobierno democrático. Alf Ross, ferviente sostenedor de la democracia representativa, así escribía en el lejano 1947, cuando justamente terminaba de entrever éxitos socialistas para la democracia: "No hay nada que nos obligue a considerar que nuestras libertades democráticas fundamentales no deberían poder adaptarse a una continua evolución en la dirección socialista" (Ross, 1947, p.403). Si bien una socialización no sea ni condición ni nota distintiva de la democracia, ella podrá bien darse. Si imagina bien: no es solamente la libertad lo que la democracia cuida.

Ninguna idea de la democracia es mensajera de la verdad. Ninguna democracia puede escapar a la inagotabilidad de las ideas y de los ideales. Incluso al coraje inquieto de las utopías. La perspectiva socio-cultural reformista de Márquez-Fernández es, en el fondo - por su propia admisión - utopística, una forma de manifiesto político, un llamado ético del hombre a las responsabilidades que le derivan del ser parte de una comunidad. Pero diría, todavía más, un conjurado llamado al "diálogo intersubjetivo" dirigido a desenmascarar los contenidos del poder del Estado hegemónico para la construcción de una "sociedad más plural y participativa" (Ross, 1947, p. 403).

Cuidado, diálogo, participación, ciudadanía popular, pluralidad, igualdad son todas determinaciones de su proyecto de socialismo utopístico, ejercicios del vivir civil. Las clases de Boaventura de Sousa Santos sobre socialismo y democracia y sobre el futuro de la utopía en las democracias latino-americanas están, con seguridad en las tramas. Pero tenga cuidado: proyecto utópico y programa político no significa, según 
Márquez-Fernández, disyunción del alma y del cuerpo, del ideal y de lo real. Utopía y política están tenidas profundamente ligadas, la una incluye, o mejor dicho, debe incluir la otra.

La utopía es la causa eficiente de un programa político que no quiere rendirse ni humillarse a los mezquinos halagos del presente "hegemónico". La utopía es conductora del diálogo, y el diálogo es coparticipación, reconocimiento, satisfacción de las expectativas "de un buen vivir para todos y todas" ${ }^{32}$. El ritmo del "pensamiento utópico" (Ross, 1947, p. 403)

Está marcado por el latido constante de la pasión y por la práctica de todos, en nuestro vivir de cada día. Y es esta la lección más noble y de extraordinaria belleza que nos ha regalado Álvaro Márquez-Fernández.

\section{Referencias Bibliográficas}

Bobbio Norberto. (2009). Eguaglianza e libertà. Eianudi, Italia.

Bobbio Norberto. (2004). Democrazia en Norberto Bobbio, Nicola Matteucci, Gianfranco Pasquino (Compiladores). Dizionario di Politica. Utet, Italia.

Bobbio Norberto. (2000). In praise of meekness. Essays on ethics and politics. Polity Press

Bobbio, Norberto. (2006). Liberalismo e democrazia. Simonelli, Italia.

Márquez-Fernández, Álvaro. (2018). Democracia sub-alterna y Estado hegemónico. Crítica política desde América Latina. El Pregonero, Argentina.

Fisher, Berenice y Tronto, Joan. (1991). Toward a feminist theory of caring, En: E. Abel, M. Nelson (Editores) Circles of care: work and identity in women's lives. State Unviersity of New York Press, Estados Unidos.

Gilligan, Carol. (1982). In a different voice. Psychological theory and womens' development, Cambridge. Harvard University Press, United Kingdon.

Gilligan, Carol. (2010). Letter to the readers. 1993. En: Id., In a different voice, Harvard University Press, 1993; C. Gilligan, Un regard prospectif à partir du passé, en: N. Nurock (por cuenta de), Carol Gilligan e l'ètique du care, Paris 2010; N. Noddings, Starting at home. Caring and social policy, USA.

Holmes Stephen, Cass Sunstein. (1999) The costs of rights: why liberty depends on taxes. W.W. Norton Comapny, Estados Unidos.

Kelsen, Hans. (1988). La democrazia. Il Mulino, Italia. 
El coraje inquieto de la utopía. De la democracia sub-alterna a la democracia del cuidado

Mackenzie, Catriona; Rogers, Wendy y Dodds, Susan (Editores) (2012). Vulnerability: new essays. En: Ethics and Feminist theory, Oxford University Press, USA.

Tronto, Joan (2013) Care democracy. Markets, equality and justice. New York University Press, Estados Unidos

Tronto, Joan (1993) Moral boundaries. A political argument for an ethic of care. Routlege, Estados Unidos. New York-London. Sobre cuidado y democracia, a partir del pensamiento feminista estadounidense, y por la comparación entre cuidado, justicia, derecho y necesidades, reenvío al mío: Hearing voices of care: ¿for a juster democracy?, en "Avant: Trends in Interdisciplinary Studies”, marzo/abril 2019, en curso de publicación.

Ross, Alf (2016) Democrazia, potere e diritto. En: Contributi al dibattito odierno (por cuenta y traducido por A. Serpe), Giappichelli, Italia.

Ross, Alf. (1947) Socialismen och Demokratin. Tiden. Vol. 39. Issue 7, Suecia (Pp. 392-404).

Serpe, Alessandro. (2015) Norberto Bobbio: un percorso tra legalità e democrazia. En: G. Acocella (Editores). Materiali per una cultura della legalità. Giappichelli, Italia. 